\title{
Estimate Land Surface Temperature in Relation to Land Use Types and Geological Formations Using Spectral Remote Sensing Data in Northeast Jordan
}

\author{
Majed Ibrahim', Haya Abu-Mallouh ${ }^{2}$ \\ ${ }^{1}$ Department of Geographic Information System and Remote Sensing, Institute of Earth and Environmental \\ Sciences, Al al-Bayt University, Mafraq, Jordan \\ ${ }^{2}$ Jordan Engineer Association, Irbid, Jordan \\ Email: majed.ibrahim@aabu.edu.jo,Haya_abumalloh@yahoo.com
}

How to cite this paper: Ibrahim, M. and Abu-Mallouh, H. (2018) Estimate Land Surface Temperature in Relation to Land Use Types and Geological Formations Using Spectral Remote Sensing Data in Northeast Jordan. Open Journal of Geology, 8, 174-185. https://doi.org/10.4236/ojg.2018.82011

Received: January 15, 2018

Accepted: February 23, 2018

Published: February 26, 2018

Copyright (c) 2018 by authors and Scientific Research Publishing Inc. This work is licensed under the Creative Commons Attribution International License (CC BY 4.0).

http://creativecommons.org/licenses/by/4.0/

(c) (i) Open Access

\begin{abstract}
Land Surface Temperature (LST) is one of the important indicators to understand the spatial changes and surface processes on the earth surface that leads to actual assessment of environmental quality from local to global scales. The relation between spatial analysis of the land surface temperature and existing land use/land cover changes is important to evaluate the climate processes. Monitoring of this relation in the arid and semi-arid regions is necessary to make an appropriate decision about Land surface temperature and environmental status. In this paper, generally the split-window algorithm is used to estimate LST from thermal bands of the Landsat Operational Land Imager (OLI) and the Thermal Infrared Sensor (TIRS) using remote sensing and Geographic Information System (GIS) techniques as well as meteorological data through Moderate Resolution Imaging Spectroradiometer (MODIS). The results show the relationships between land use types and land surface temperature. MODIS data were analyzed. The relationship between MODIS and Landsat data temperature is moderate relation and the $(\mathrm{R} 2=0.5109)$ according on 200 random points were selected. This research concludes that the maximum temperatures of the land use types in MODIS and Landsat data for the rock formation are $59^{\circ}$ and $45^{\circ}$ respectively, whereas the maximum temperatures of the geological formation in MODIS and Landsat data for the basalt are $59^{\circ}$ and $45^{\circ}$ respectively. In conclusion, the MODIS and Landsat OLI and TIRS Data have high ability to distinguish the land use types. The correlation coefficient of the relation between the surface temperature with rock was $(\mathrm{R} 2=0.6197)$. Therefore, it is found that there is an ability to monitor the
\end{abstract}


spatial and temporal changes for land surface temperature and thus it can be useful to environmental studies.

\section{Keywords}

Land Surface Temperature, MODIS, Land Use Type, Geological Formation, Remote Sensing

\section{Introduction}

Global environmental processes to understand climate changes has been studied for over a decade using Land Surface Temperature considered as a good indicator to monitor physical properties of surface processes and climate changes for this reason also LST is an important model of the energy balance at the surface, which means that the LST has a significant role to the effect on environmental processes [1] [2] [3] [4] and this effect occurs in the land surface by different natural and human activities.

LST has a significant impact on analyzing the environmental issues such as urban heat islands, soil moisture, urban heat islands and vegetation which play role in exchanging bioprocesses of water and energy between land surface and air [1] [5]-[10], which are related to the surface temperature (surface heat) [5]. This leads to having different land-use/cover types or surface materials which have several effects on LST from local to global scales.

Moreover, estimate LST is useful to study areas that witness changes and activities in land types and surface materials, which located in the arid and semi-arid areas [5] [11], because high temperature decreases energy activity used in cooling building in hot months [5] [12]. On the other hand, high temperature in these arid and semi-arid regions evaporates water, decreases probability of vegetation growing and increases soil erosion activity.

Furthermore, it's found that the relation between Spatial distribution of the LST and surface materials and land use/land cover types is good indicator to evaluate general ecosystem and environmental status. LST is estimated using different remote sensing data in many fields such as; forestry, vegetation, climate change hydrology, oceanography, urban heat island and climate [13] [14] [15], where the remote sensing has high techniques which evaluate and monitor environmental changes [1]. In this case, Landsat is used as one of the widely remote sensors used, Landsat 8 follow the Landsat series which provides thermal data [1] [16]. LST is investigated by meteorological data, Moderate Resolution Imaging Spectroradiometer (MODIS) one of the most remote sensing data range which is considered one of the important meteorological data from space, where MODIS used to evaluate estimated LST from TIRS of Landsat.

Many researchers use algorithms to estimate LST from remote sensing such as Split-Window algorithm (SW), Dual Angle algorithm (DA), Single-Channel algorithm (SC) [17]. Split-Window algorithm is used in this study where suitable 
with provided data of TIRS Landsat 8 . This study aims at using spectral remote sensing data (TIRS and MODIS data) to estimate Land surface temperature in relation to Land use types and geological formation in northeast Jordan.

\section{Methodology and Materials}

\subsection{Study Area and Data Used}

The study area is located in north-east of Jordan as shown in Figure 1, where the study area has a semi-arid climate of the Mediterranean region with a limited amount of rainfall and high temperatures. Its weather is cold and rainy from October to April, dry and hot from May to September. The annual rainfall is $152.1 \mathrm{~mm}$. The mean minimum temperature is $12^{\circ} \mathrm{C}$ and the mean maximum temperature is $26.9^{\circ} \mathrm{C}$. The annual relative humidity is $49.7 \%$ according WMO (2017) [18] [19].

The main source of data in this research are satellite images from Landsat 8 OLI (Operational Land Imager), TIRs (Thermal Infrared Sensor) and MODIS imagery (Moderate Resolution Imaging Spectroradiometer) which downloaded free from the United States Geological Survey (USGS) Global Visualization (GloVis) site. These data were acquired in the same seasonal period (April 2015). Moreover, geological map was used to find relationship between LST and geological formation that covered study area which was obtained from Natural Resources Authority (NRA). Many software were used in order to pre-processing these data software such as: ERDAS IMAGINE 2014 to pre-processing and processing images, GIS techniques to get land use/land cover using one of the classification approaches, accuracy assessment and to apply LST equation and find correlation $\mathrm{R}$ studio to statistics analysis.

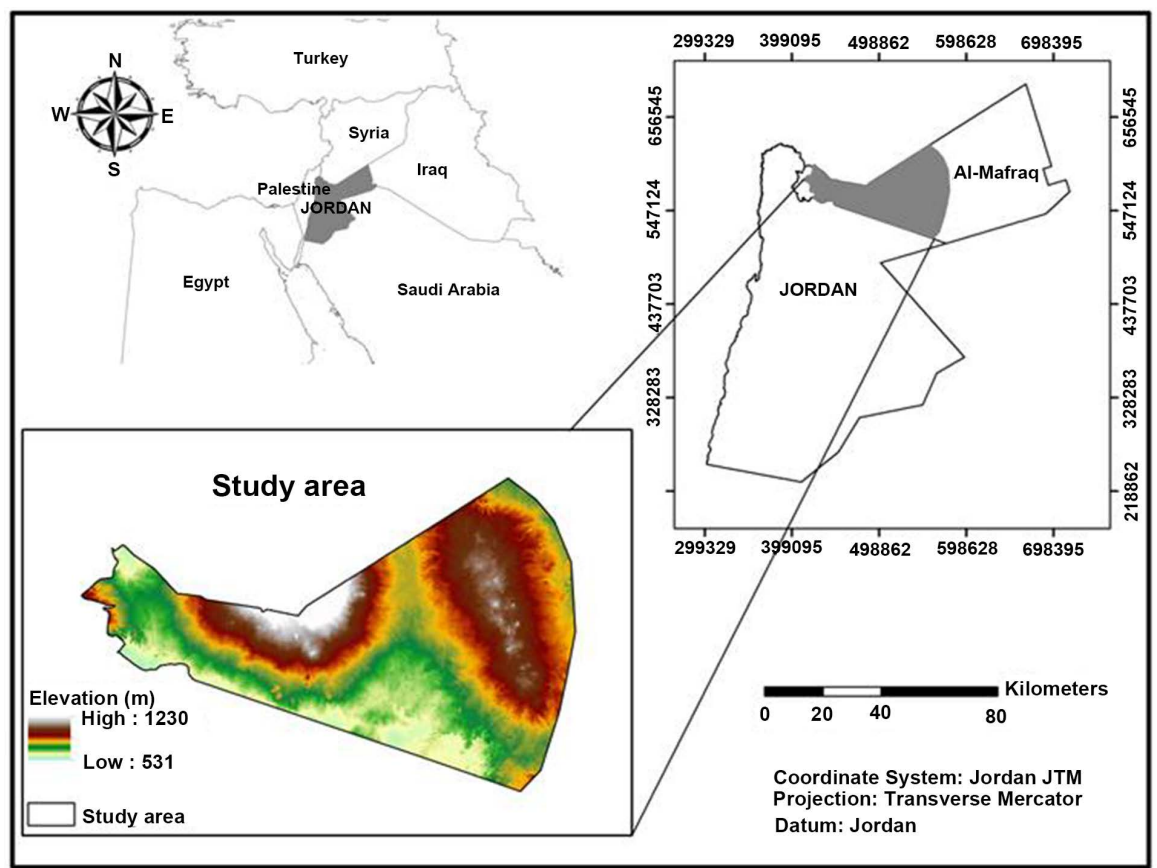

Figure 1. Location of study area. 


\subsection{Methods}

The methodology applied in this research is illustrated in Figure 2. First, the raw data of remote sensing are used to carry out some processes. Second, the spectral indices are applied to carry out equations of LST, the land use type is extracted from Landsat 8 OLI, MODIS is used as reference data, all these were used to estimate land surface temperature.

\subsubsection{Image Processing}

There are a several ways of calculating and estimating land surface temperature (LST), different algorithms to do that like Split-Window (SW), Dual-Angle (DA), Single-Channel (SC). In this study we will use the Split-Window, the thermal bands and NDVI are acquired for the study area [20] [21] [22]. The (Equation (1)) of LST is:

$$
L S T=B T / 1+(W * B T / P * \ln (e))
$$

where:

LST: Land Surface Temperature.

BT: Brightness Temperature.

$W$ : Wavelength.

P. 1438

e/ LSE: Land Surface Emissivity.

\subsubsection{Brightness Temperature (BT)}

Brightness temperature is the temperature of a blackbody which is used to produce the radiance perceived by the sensor, according NASA 2012 [23]. Moreover,

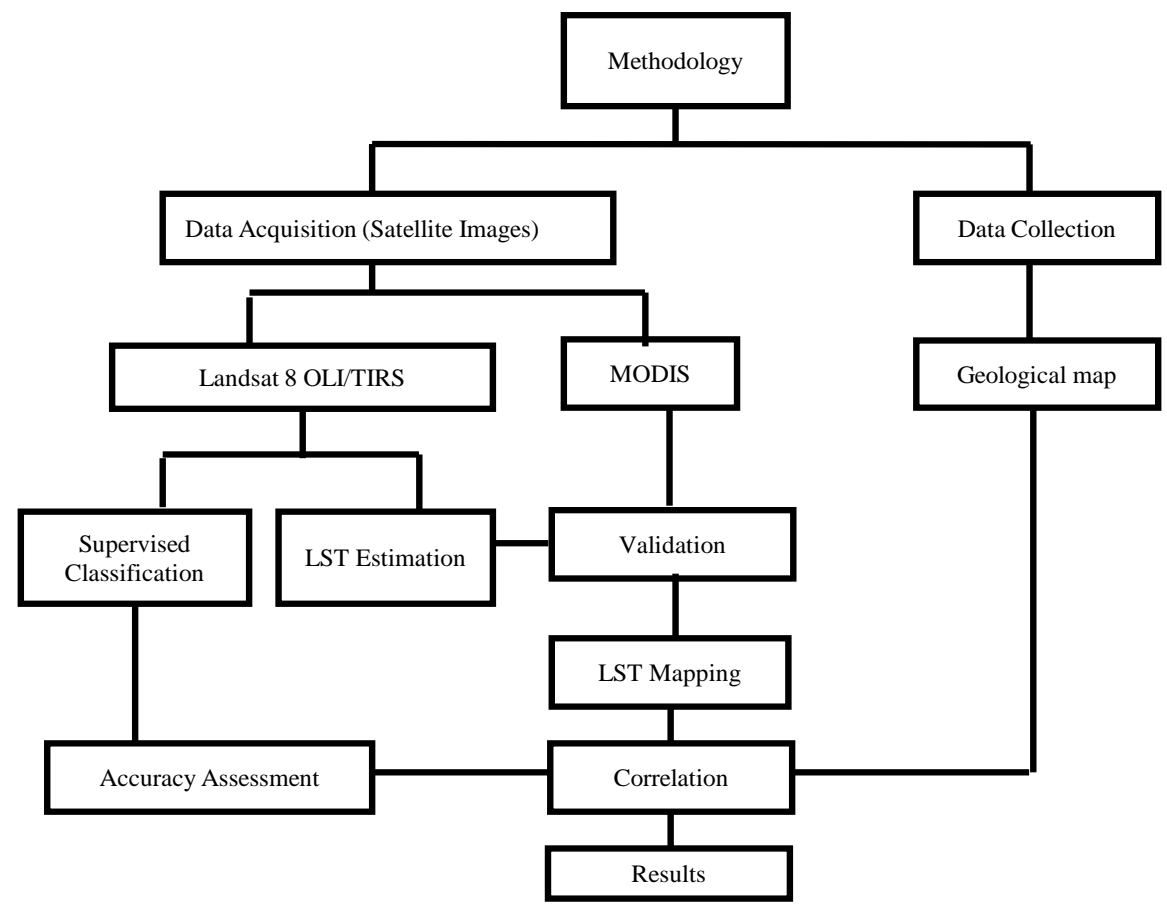

Figure 2. Methodology flow chart of the study. 
it is the temperature that been received by the satellite at the time that the image was taken. Therefore, this is not the real temperature on the ground; it's the temperature at satellite [22]. TIRS band data can be converted from spectral radiance to brightness temperature using the thermal constants provided in the metadata file, the (Equation (2)) used to convert from spectral radiance to brightness temperature.

$$
T=\frac{K_{2}}{\ln \left(\frac{k_{1}}{l \lambda}+1\right)}-272.15
$$

where:

$K_{1}$ and $K_{2}$ : Thermal constant.

$L \lambda$ : Top of Atmospheric spectral radiance (TOA).

Landsat 8 provides some constant to estimate LST such as thermal constant and rescaling factor; it found it in metadata file of Landsat satellite images (Table 1, Table 2).

Now, to find the Brightness Temperature (BT), the Top Of Atmospheric spectral radiance (TOA) is acquired. The Equation (3) states:

$$
L \lambda=M L * Q c a l+A L
$$

where:

$M L$ : Band specific multiplicative rescaling factor (radiance_mult_band_10/11).

$A L$ : Band specific additive rescaling factor (radiance_add_band_10/11).

Qcal: band 10/11 image.

\subsubsection{Land Surface Emissivity}

Land surface emissivity is a relative factor that estimates blackbody radiance that is measured from land surface temperature [24]. There are several ways to estimate land surface emissivity (Equation (4)). One of them is Normalized Difference Vegetation Index (NDVI) method, taking into account the proportion vegetation $\left(P_{V}\right)$, then LST in Celsius is determined. The formula of land surface emissivity is "Equation (5)".

$$
\begin{gathered}
e=0.004 * P V+0.9 \\
P v=\left(\frac{N D V I-N D V I \min }{N D V I \max -N D V I \min }\right)^{2}
\end{gathered}
$$

Table 1. K1 and K2 values [16].

\begin{tabular}{ccc}
\hline Thermal Constant & Band 10 & Band 11 \\
\hline K1 & 1321.08 & 1201.14 \\
K2 & 774.89 & 480.89 \\
\hline
\end{tabular}

Table 2. Rescaling factor [16].

\begin{tabular}{ccc}
\hline Rescaling Factor & Band 10 & Band 11 \\
\hline $\mathrm{ML}$ & 0.000342 & 0.000342 \\
$\mathrm{AL}$ & 0.1 & 0.1 \\
\hline
\end{tabular}


where: el LSE: Land Surface Emissivity. Pr. Proportion of vegetation. NDVI: Normalized Differences Vegetation Index.

\subsubsection{Image Classification}

Satellite data was downloaded from USGS Earth explorer. Supervised classification was used to land use map, which is considered most common technique of classification approaches [25]. These techniques are required to define the training samples for each class and creating the spectral signature where 200 points were samples.

\subsection{Accuracy Assessments}

The accuracy assessments provide more information on where the errors of classification happened. To know how much a classification is accurate, a set of random points must be created to evaluate the data, at the location of each random point. The result would be finding the type of land use of that spot using Google earth (truth points) and comparing it to land use of the classified raster [26]. Three standard criteria were used to assess the accuracy of the classifications (overall accuracy, producer's accuracy and user's accuracy) [27].

\section{Result and Discussion}

\subsection{Relationship between the Observation Surface Temperature and Estimated LST}

In the present study, land surface temperature was estimated by the single-channel from TIRS (Thermal Infrared Sensor) data of the Landsat 8 OLI and the observation surface temperature from MODIS satellite data. The spatial distribution of estimated LST in the Figure 3, surface temperature (LST image) ranged from $24^{\circ} \mathrm{C}$ to $51^{\circ} \mathrm{C}\left(\right.$ mean $\left.=38^{\circ} \mathrm{C}\right)$ in the Figure 3 , high surface temperatures are shown by the dark red areas which mean the far northeast part of the study area have a higher temperature than the other part of the study area.

While the spatial distribution of observation surface temperature in the Figure 4 , surface temperature (LST image) ranged from $42^{\circ} \mathrm{C}$ to $59^{\circ} \mathrm{C}\left(\right.$ mean $=46^{\circ} \mathrm{C}$ ). In the Figure 4, high surface temperatures are shown by the dark red areas. This result matches with results of the estimated LST.

Statistical regression analysis was used to established relationship between observation surface temperature values and estimated LST values. The result was analyzed using 200 control points, and the correlation coefficient between two different types of surface temperature values (observation surface temperature values and estimated LST values) was $\mathrm{R}^{2}=0.51$ at the same time for the satellites passed over the study area as shown in Figure 5. The difference between the observation temperature values and estimated LST values is due to the difference in the spatial resolution between sources data and surface roughness effects on the surface temperature [28]. Points out that atmospheric impurities can be effect to the surface temperature. 


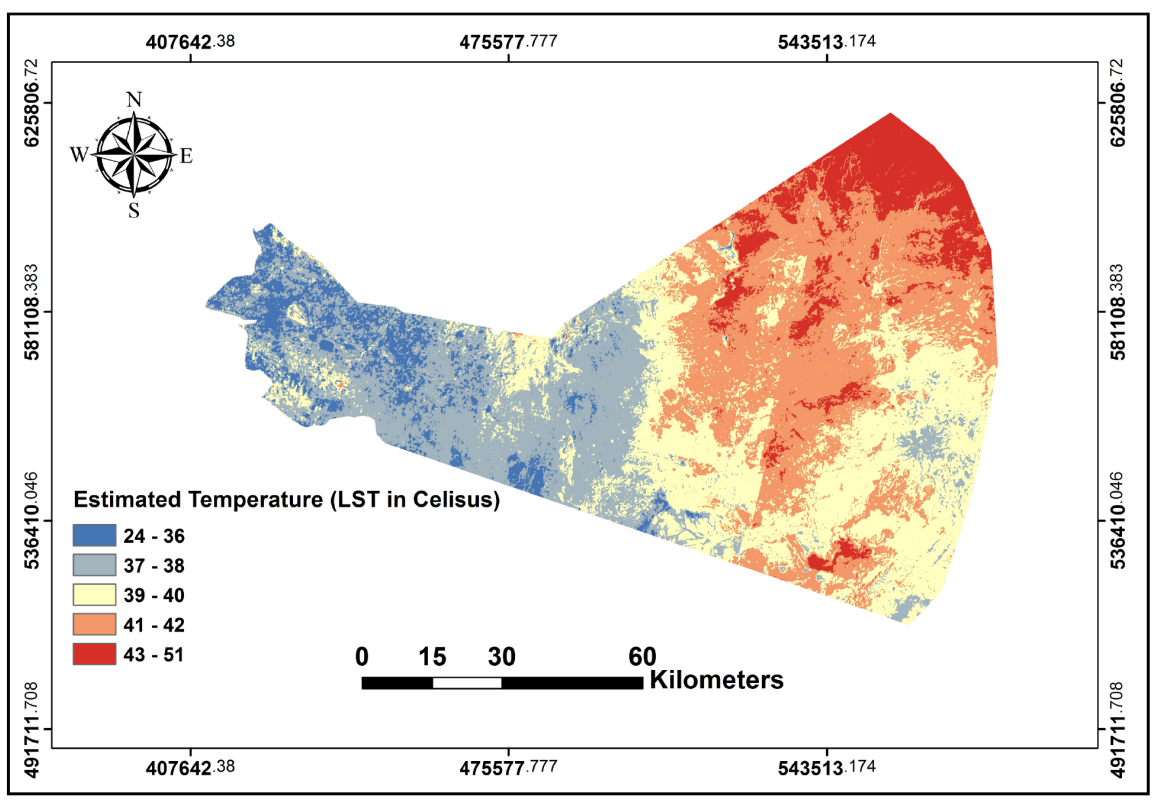

Figure 3. Final estimated land surface temperature (LST) of the study area.

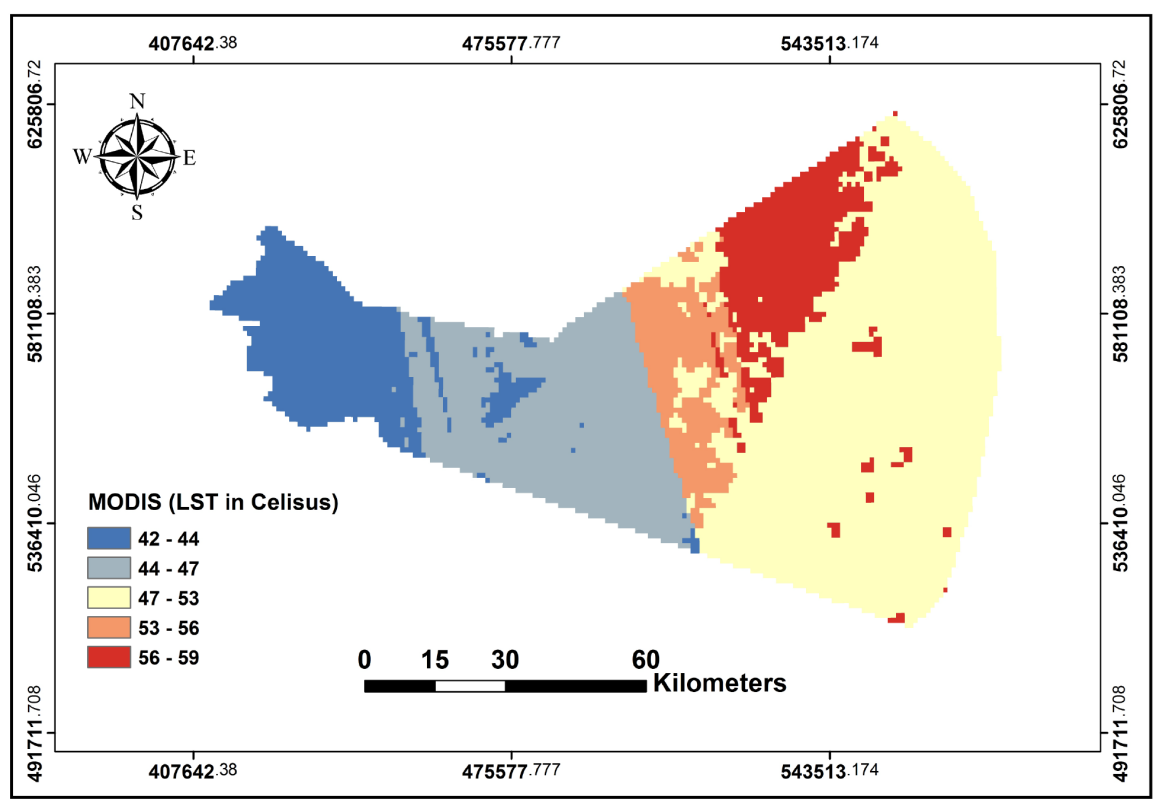

Figure 4. Observation surface temperature of the study area (MODIS image).

\subsection{Relationship Estimated LST and Land Use Changes}

Four land use types resulted from classification of the image for the study area, shown in the Figure 6. These classes were considered rock, soil, agriculture and urban. For example, by comparing the reference and classified data in the Table 3 , it was observed that $82.35 \%$ (user accuracy percent) of the rock were being correctly identified as rock, while $66.67 \%$ (produces accuracy percent) of the areas called rock are actually rock. Kappa coefficient values of the classified image were 0.73 and overall accuracy was $80 \%$. This accuracy assessment test made to know how the classification is accurate and these values were obtained from 


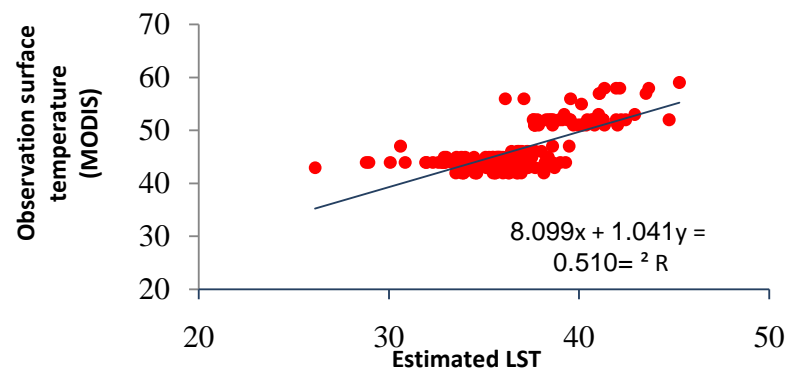

Figure 5. Relationship between the observed surface temperature and estimated LST.

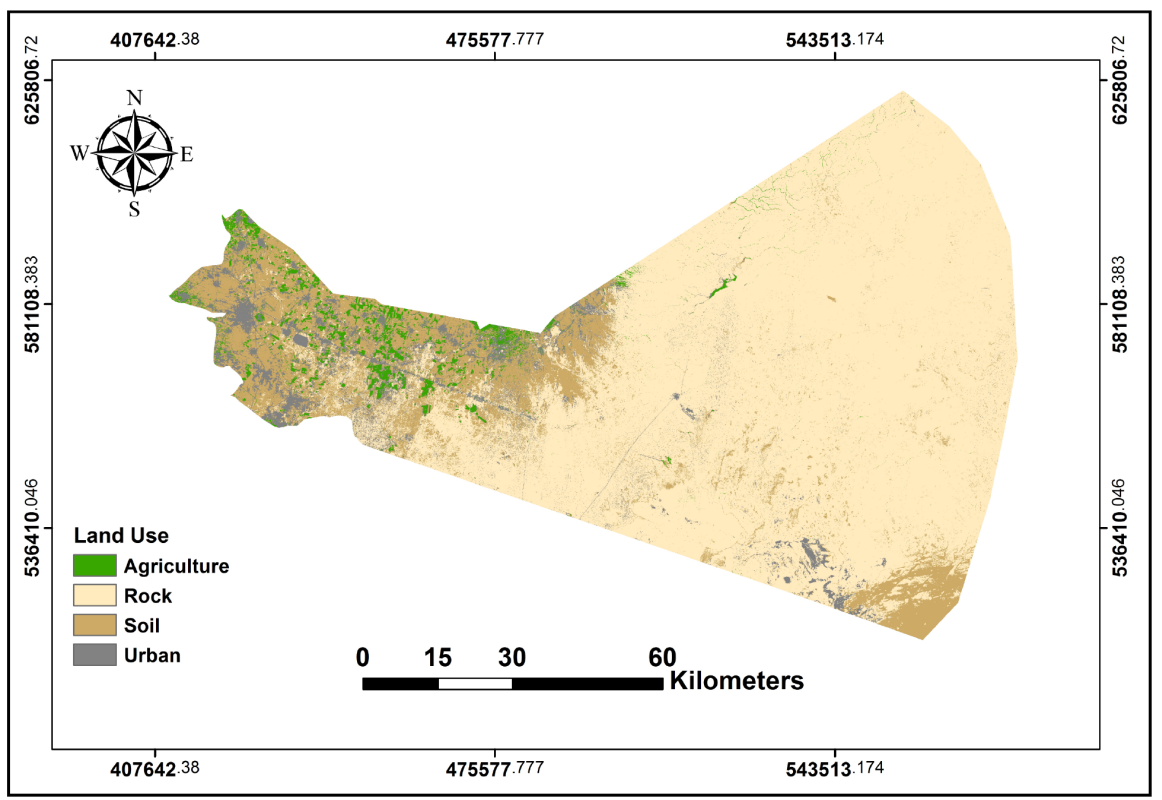

Figure 6. Land use map of study area (Landsat April 2015).

Table 3. Classification accuracy assessment report.

\begin{tabular}{|c|c|c|}
\hline Land use classes & Produces accuracy & User accuracy \\
\hline Rock & $66.67 \%$ & $82.35 \%$ \\
\hline Soil & $75.47 \%$ & $81.63 \%$ \\
\hline Agriculture & $89.80 \%$ & $86.27 \%$ \\
\hline Urban & $97.14 \%$ & $69.39 \%$ \\
\hline Over accuracy & \multicolumn{2}{|c|}{$80 \%$} \\
\hline
\end{tabular}

analysis of the reference data (truth points) and the classification output Figure 6 and Table 3.

In the classified image, classes have minimum, maximum mean and standard deviation (SD) values of observed surface temperature and estimated LST Table 4. For the investigate area, results show that the observed surface temperature and estimated LST from single-channel algorithm using Landsat OLI/TIRS sensor data have high accuracy with minimum, maximum mean and standard 
Table 4. Land surface temperature of different land use classes of study area.

\begin{tabular}{cccccccccc}
\hline & \multicolumn{3}{c}{ LST } & \multicolumn{7}{c}{ MODIS } \\
\hline Classes & $\operatorname{Min}\left({ }^{\circ} \mathrm{C}\right)$ & $\operatorname{Max}\left({ }^{\circ} \mathrm{C}\right)$ & $\operatorname{Mean}\left({ }^{\circ} \mathrm{C}\right)$ & $\mathrm{SD}$ & $\operatorname{Min}\left({ }^{\circ} \mathrm{C}\right)$ & $\operatorname{Max}\left({ }^{\circ} \mathrm{C}\right)$ & $\operatorname{Mean}\left({ }^{\circ} \mathrm{C}\right)$ & $\mathrm{SD}$ & $\mathrm{R}^{2}$ \\
\hline Rock & 36 & 45 & 40 & 2 & 43 & 59 & 51 & 4 & 0.99 \\
Soil & 34 & 41 & 37 & 1 & 42 & 56 & 45 & 3 & 0.98 \\
Agriculture & 29 & 39 & 35 & 2 & 42 & 59 & 44 & 1 & 0.98 \\
Urban & 26 & 41 & 35 & 3 & 42 & 56 & 45 & 3 & 0.97 \\
\hline
\end{tabular}

deviation (SD), where the $\mathrm{R}^{2}$ are $0.99,0.98,0.98$ and 0.97 for rock, soil, agriculture and urban respectively Table 4 . On the other hand the results show that these data have low accuracy with 50 control points for each class except rock class has good accuracy where the R2 are $0.62,0.23,0.02$ and 0.26 for the rock and soil, agriculture and urban respectively.

\subsection{Relationship Estimated LST and Geological Formations}

Four geological formations in the study area were geologically exposed according NRA (1997) [29], as shown in Figure 7 and these formations were considered: basalt, WadiAlshalla, Muwqqar and Rijam. These formations have minimum, maximum mean and standard deviation (SD) values of observed surface temperature and estimated LST (Table 5). The results show that the observed surface temperature and estimated LST values for these formation has high accuracy with minimum, maximum mean and standard deviation (SD), where the $\mathrm{R}^{2}$ are $0.98,0.99,0.97$ and 0.99 for rock, basalt, WadiAlshalla, Muwqqar and Rijam, respectively (Table 5).

It's generally observed that surface temperature has been increased in all types of land use and all type of geological formations, but the good increase in types of land use which was registered is rock type, and it should be noted that agriculture and urban had experienced a slight decrease over average temperatures. This is may be due to source cooling like water for the agriculture or cultivated area that mean in general the relationship between vegetation cover was weak, by increasing vegetation cover the surface temperature will decrease, and materials of building that help to reflect energy or cooling devices in the summer season where this area is considered one of the arid and semi-arid for high temperature in most months of the year.

While highest increase in the geological formation which was registered is basalt, and the other formation had slight decrease over average temperatures. This is probably because of the chemical components of the basalt. Other formation had experienced a slight decrease over average temperatures This may be because of the weak relationship between the minerals content of these formation and energy which lead to reflect energy or minerals have ability to store water which lead to decrease land temperature by cooling. 


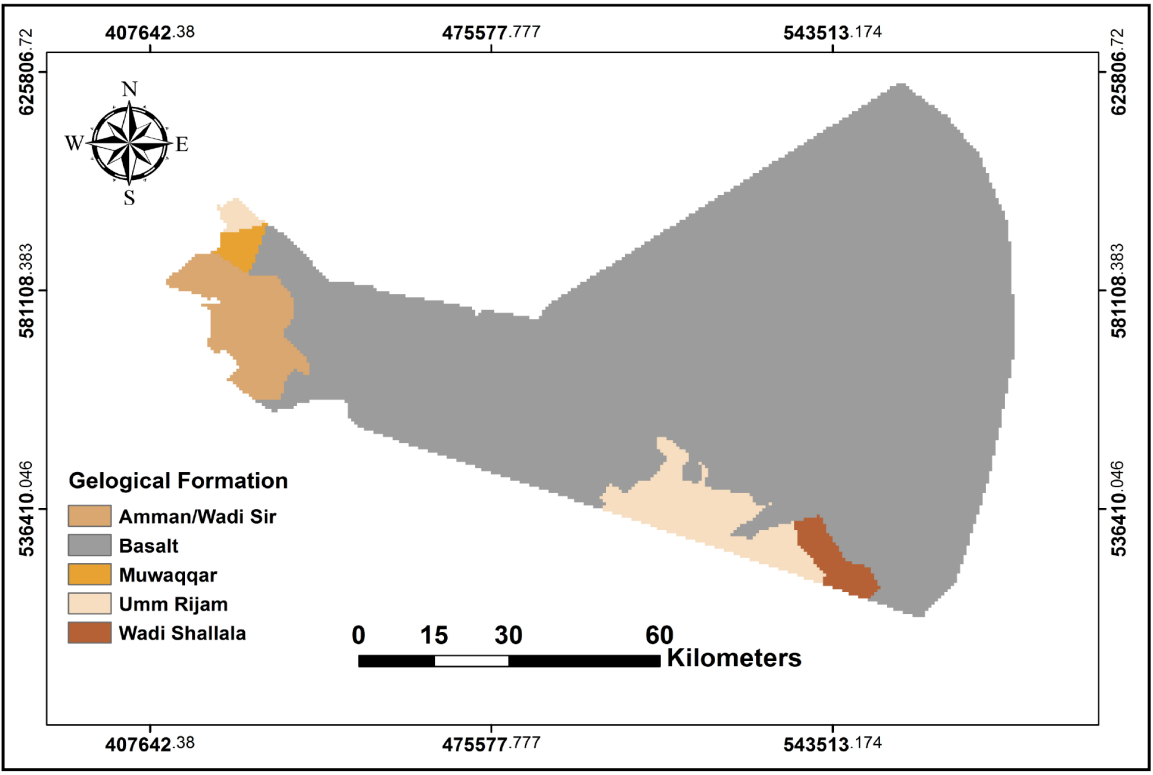

Figure 7. Geological formation map for study area (NRA, 1997).

Table 5. Land surface temperature of different land use classes of study area.

\begin{tabular}{cccccccccc}
\hline \multicolumn{7}{c}{$\mathrm{LST}$} \\
\hline Formation & $\operatorname{Min}\left({ }^{\circ} \mathrm{C}\right)$ & $\operatorname{Max}\left({ }^{\circ} \mathrm{C}\right)$ & $\operatorname{Mean}\left({ }^{\circ} \mathrm{C}\right)$ & $\mathrm{SD}$ & $\operatorname{Min}\left({ }^{\circ} \mathrm{C}\right)$ & $\operatorname{Max}\left({ }^{\circ} \mathrm{C}\right)$ & $\operatorname{Mean}\left({ }^{\circ} \mathrm{C}\right)$ & $\mathrm{SD}$ & $\mathrm{R}^{2}$ \\
\hline Basalt & 29 & 45 & 37 & 3 & 42 & 59 & 48 & 0.98 \\
WadiAlshalla & 38 & 41 & 39 & 4 & 51 & 52 & 51 & 0.99 \\
Muwqqar & 30 & 36 & 34 & 2 & 43 & 44 & 44 & 0.97 \\
Rijam & 31 & 41 & 36 & 3 & 42 & 56 & 46 & 0.99 \\
\hline
\end{tabular}

\section{Conclusions}

Split-window algorithm, a mathematical way to provide the land surface temperature (LST) information using brightness temperature of thermal bands of TIRS sensor and land surface emissivity (LSE) factor, is derived from proportion vegetation (pv) of optical bands of OLI sensor.

The land use map of the study area is developed by supervised classification of the images. Four land use classes have been identified as rock, soil, agriculture and urban. Over all classification accuracy is $80 \%$. From the LST images, it is clearly understood that surface temperature is more in rock area. Also the correlation study shows the moderate relation between the LST and MODIS. Thus, LST can be calculated using SW algorithm on Landsat 8 with multiband OLI and TIR images. On the other hand, this algorithm has ability to show the variation of the land temperature between different geological formations, and is concluded that the estimated LST is a good way to monitor hydrothermal dynamic if is provided good data and techniques.

\section{Acknowledgements}

The authors are highly grateful and thankful to the USGS/Landsat for providing 
the free data and thankful to $\mathrm{Al}$ al-Bayt University.

\section{References}

[1] Zaharaddeen, I, Baba, I.I. and Zachariah, A. (2016) Estimation of Land Surface Temperature of Kaduna Metropolis, Nigeria Using Landsat Images. Science World Journal, 11, 36-42.

[2] Akhoondzadeh, M. and Saradjian, M.R. (2008) Comparison of Land Surface Temperature Mapping Using MODIS and ASTER Images in Semi-Arid Area. The International Archives of the Photogrammetry, Remote Sensing and Spatial Information Sciences, 37, 873-876.

[3] Weng, Q., Lu, D. and Schubring, J. (2004) Estimation of Land Surface Temperature-Vegetation Abundance Relationship for Urban Heat Island Studies. Remote sensing of Environment, 89, 467-483. https://doi.org/10.1016/j.rse.2003.11.005

[4] Dousset, B. and Gourmelon, F. (2003) Satellite Multi-Sensor Data Analysis of Urban Surface Temperatures and Landcover. ISPRS Journal of Photogrammetry and Remote Sensing, 58, 43-54. https://doi.org/10.1016/S0924-2716(03)00016-9

[5] Zareie, S., Khosravi, H., Nasiri, A. and Dastorani, M. (2016) Using Landsat Thematic Mapper (TM) Sensor to Detect Change in Land Surface Temperature in Relation to Land Use Change in Yazd, Iran. Solid Earth, 7, 1551.

https://doi.org/10.5194/se-7-1551-2016

[6] Srivastava, P.K., Han, D., Ramirez, M.R. and Islam, T. (2013) Machine Learning Techniques for Downscaling SMOS Satellite Soil Moisture Using MODIS Land Surface Temperature for Hydrological Application. Water Resources Management, 27, 3127-3144. https://doi.org/10.1007/s11269-013-0337-9

[7] Song, X., Leng, P., Li, X., Li, X. and Ma, J. (2013) Retrieval of Daily Evolution of Soil Moisture from Satellite-Derived Land Surface Temperature and Net Surface Shortwave Radiation. International Journal of Remote Sensing, 34, 3289-3298. https://doi.org/10.1080/01431161.2012.716915

[8] Bateni, S.M., Entekhabi, D. and Castelli, F. (2013) Mapping Evaporation and Estimation of Surface Control of Evaporation Using Remotely Sensed Land Surface Temperature from a Constellation of Satellites. Water Resources Research, 49, 950-968. https://doi.org/10.1002/wrcr.20071

[9] Wong, M.S. and Nichol, J.E. (2013) Spatial Variability of Frontal Area Index and Its Relationship with Urban Heat Island Intensity. International Journal of Remote Sensing, 34, 885-896. https://doi.org/10.1080/01431161.2012.714509

[10] Bastiaanssen, W.G., Menenti, M., Feddes, R.A. and Holtslag, A.A. (1998) A Remote Sensing Surface Energy Balance Algorithm for Land (SEBAL). 1. Formulation. Journal of Hydrology, 31, 198-212. https://doi.org/10.1016/S0022-1694(98)00253-4

[11] Mallick, J., Kant, Y. and Bharath, B.D. (2008) Estimation of Land Surface Temperature over Delhi Using Landsat-7 ETM+. Journal of Indian Geophysical Union, 12, 131-140.

[12] Santamouris, M., Papanikolaou, N., Livada, I., Koronakis, I., Georgakis, C., Argiriou, A. and Assimakopoulos, D.N. (2001) On the Impact of Urban Climate on the Energy Consumption of Buildings. Solar Energy, 70, 201-216. https://doi.org/10.1016/S0038-092X(00)00095-5

[13] Ngie, A., Abutaleb, K., Ahmed, F., Taiwo, O.J., Darwish, A.A. and Ahmed, M. (2016) An Estimation of Land Surface Temperatures from Landsat ETM+ Images for Durban, South Africa. Rwanda Journal, 1. http://dx.doi.org/10.4314/rj.v1i2S.2D 
[14] Orhan, O. and Yakar, M. (2016) Investigating Land Surface Temperature Changes Using Landsat Data in Konya, Turkey. International Archives of Photogrammetry, Remote Sensing and Spatial Information Sciences, XLI-B8, 285-289. https://doi.org/10.5194/isprsarchives-XLI-B8-285-2016

[15] Orhan, O., Ekercin, S. and Dadaser-Celik, F. (2014) Use of Landsat Land Surface Temperature and Vegetation Indices for Monitoring Drought in the Salt Lake Basin Area, Turkey. The Scientific World Journal, 2014, Article ID: 142939. https://doi.org/10.1155/2014/142939

[16] NASA (2015) Landsat 8 Science Data Users Handbook (United States). http://landsat.usgs.gov/landsat8.php

[17] Latif, M.S. (2014) Land Surface Temperature Retrieval of Landsat-8 Data Using Split Window Algorithm-A Case Study of Ranchi District. International Journal of Engineering Development and Research, 2, 3840-3849.

[18] WMO (2017) World Meteorological Organization. http://worldweather.wmo.int/en/city.html?cityId=590

[19] Ibrahim, M. (2016) Modeling Soil Salinity and Mapping Using Spectral Remote Sensing Data in the Arid and Semi-Arid Region. International Journal of Remote Sensing Applications, 6, 76-83. https://doi.org/10.14355/ijrsa.2016.06.008

[20] Rajeshwari, A. and Mani, N.D. (2014) Estimation of Land Surface Temperature of Dindigul District Using Landsat 8 Data. International Journal of Research in Engineering and Technology, 3, 2319-1163.

[21] Ghulam, A. (2010) Calculating Surface Temperature Using Landsat Thermal Imagery. PhD Thesis, Department of Earth \& Atmospheric Sciences, and Center for Environmental Sciences, Saint Louis University, St. Louis, MO.

[22] Alipour, T., Sarajian, M.R. and Esmaeily, A. (2003) Land Surface Temperature Estimation from Thermal Band of Landsat Sensor, Case Study: Alashtar City. The International Achieves of the Photogrammetry, Remote Sensing and Spatial Information Sciences, 38.

[23] NASA (2012) National Aeronautics and Space Administration. Goddard Earth Sciences (GES) Data and Information Services Center (DISC).

https://daac.gsfc.nasa.gov/

[24] Sobrino, J.A., Jiménez-Muñoz, J.C., Sòria, G., Romaguera, M., Guanter, L., Moreno, J., Plaza, A. and Martínez, P. (2008) Land Surface Emissivity Retrieval from Different VNIR and TIR Sensors. IEEE Transactions on Geoscience and Remote Sensing, 46, 316-327. https://doi.org/10.1109/TGRS.2007.904834

[25] Gillespie, A. (2014) Land Surface Emissivity. In: Njoku, E.G., Ed., Encyclopedia of Earth Sciences Series-Encyclopedia of Remote Sensing, Springer, New York. https://doi.org/10.1007/978-0-387-36699-9

[26] Jensen, J.R. (2016) Introductory Digital Image Processing: A Remote Sensing Perspective. No. Ed. 4, Prentice-Hall Inc., Upper Saddle River.

[27] Lillesand, T., Kiefer, R.W. and Chipman, J. (2014) Remote Sensing and Image Interpretation. John Wiley \& Sons, Hoboken.

[28] Brooks, D.R. (2006) Monitoring Solar Radiation and Its Transmission through the Atmosphere. The GLOBE Program 2.

http://www.pages.drexel.edu/ brooksdr/DRB_web_page/papers/UsingTheSun/usin g.htm

[29] NRA (1997) Natural Resources associate. National Geological Mapping Project. Prepared by Ahmad A Smadi in 1997. 